\title{
N11 Ülkelerinde Ekolojik Ayak İzi Yakınsaması: Fourier Durağanlık Testinden Yeni Kanıtlar
}

Araştırma Makalesi /Research Article

\section{Süleyman YURTKURAN ${ }^{1}$}

ÖZ: Çevresel kirlilik çalışmalarında kullanılan durağanlık testleri çevresel politikalar belirlemede yardımcı olmaktadır. Çevresel kirlilik göstergesi olarak belli başlı değişkenler bulunmaktadır. Bu değişkenlerden bir tanesi de kapsaml bir gösterge olan ekolojik ayak izidir. Bu çalışma 1971-2016 döneminde N11 olarak da bilinen yeni endüstrileşen ülkelerde kişi başına düşen ekolojik ayak izinin yakınsamasını test etmeyi amaçlamaktadır. Bu amaçla panel Yatay Kesitsel Genişletilmiş Dickey-Fuller birim kök testi ve yeni geliştirilen panel Fourier durağanlık testi kullanılmıştır. Elde edilen sonuçlara göre Endonezya, Pakistan ve Filipinler'de ekolojik ayak izi göstergesi durağan olmaktadir. Bu durum bu ülkelerde yakınsama olduğunu göstermektedir. Türkiye, Bangladeş, Misır, İran, Meksika, Nijerya, Güney Kore ve Vietnam'da ise çevresel kirlilikte meydana gelen şokların etkisi kalıcı olmaktadır. Dolayısıyla bu sekiz ülkede politika yapıcıların çevresel politikaları yeniden düzenlemeleri önem arz etmektedir.

Anahtar Kelimeler: Ekolojik Ayak İzi, Fourier Durağanlık Testi, N11

JEL Kodu: C23, Q56

\section{Ecological Footprint Convergence in N11 Countries: Fresh Evidence from Fourier Stationarity Test}

\begin{abstract}
Stationary tests in environmental pollution studies help to determine environmental policies. There are certain variables as indicators of environmental pollution. One of these variables is the ecological footprint variable, which is a comprehensive indicator. This study aims to test convergence of per capita ecological footprint in newly industrialized countries also known as the N11 cover the period of 1971-2016. For this purpose, panel Cross-sectional Augmented Dickey Fuller unit root and newly developed panel Fourier stationary test are used. The results conclude that per capita ecological footprint is stationary in Indonesia, Pakistan and Philippines. There is evidence for convergence in these countries. Shock's effects on environmental pollution are permanent in Turkey, Bangladesh, Egypt, Iran, Mexico, Nigeria, South Korea and Vietnam. Therefore, in these eight countries policy makers need to reorganize environmental policies.
\end{abstract}

Keywords: Ecological Footprint, Fourier Stationary Test, N11

JEL Codes: C23, Q56

\footnotetext{
${ }^{1}$ Dr., Milli Eğitim Bakanlığı, suleymanyurtkuran @ hotmail.com, orcid.org/0000-0002-7085-9203.
} 


\section{Giriş}

Atmosferik karbondioksit $\left(\mathrm{CO}_{2}\right)$ konsantrasyonundaki mevcut artış, küresel 1sınma ve iklim değişikliğinin en önemli nedenlerinden biridir (Pata, 2019: 20264). Son yıllarda, artan iklim değişikliği belirtileri ve küresel 1sınma kavramları çevre bilincinin artmasına katkıda bulunmuştur. 2015 yılında iklim değişikliği ve küresel 1sınma konularının da yer aldığ 1 Paris Konferansı düzenlenmiştir. $\mathrm{Bu}$ konferansta ortalama küresel sicaklığın $2^{\circ} \mathrm{C}$ 'nin üzerine çıkmaması ve endüstri öncesi devirden en fazla $1,5^{\circ} \mathrm{C}$ derece fazla olması hedeflenmiştir. Endüstri öncesi 280 ppm olan atmosferik $\mathrm{CO}_{2}$ değeri günümüzde yaklaşı \% \% 43 'lük bir yükselişle 400 ppm'yi aşmıştır ve bu değerle birlikte küresel ortalama sıcaklık $0,85^{\circ} \mathrm{C}$ artış göstermiştir (Damatta vd., 2019: 167). Yüz yıllık bir süreçte ise küresel 1sınmada ortalama olarak $0,6^{\circ} \mathrm{C}$ 'lik bir artış yaşanmıștır. Gelecek 100 yılda da bu değerin $1,1-6,4^{\circ} \mathrm{C}$ arasında artış göstereceği öngörülmektedir (IPCC, 2007). Bu yüzden başta $\mathrm{CO}_{2}$ gazı olmak üzere sera gazlarındaki artışın tüm dünyayı olumsuz yönde etkilediği görüşü hakimdir (Javid ve Sharif, 2016: 406; Yurtkuran ve Terzi, 2018: 268). Bununla birlikte çevresel kirliliğinin giderek artması ekosistemin dengesini bozarak iklim değişikliğine sebebiyet vermektedir. Çevresel kirlilik üzerine yapılan çalışmaların çoğunda, çevresel bozulmanın bir göstergesi olarak $\mathrm{CO}_{2}$ emisyonlarının kullanılmasına odaklanılmıştır (Salahuddin vd., 2015; Wang vd., 2016; Pata, 2018: 773; Destek ve Sarkodie, 2019: 2484). Bununla birlikte, $\mathrm{CO}_{2}$ emisyonları bozulma göstergesinin yalnızca bir parçasıdır. $\mathrm{CO}_{2}$ emisyonlarının ötesinde, orman arazisi kullanımı, madencilik ve petrol stokları, doğayı büyük bir baskı altına sokmaktadır (Solarin, 2019: 6167). Dolayısıyla $\mathrm{CO}_{2}$ emisyonları da dahil olmak üzere spesifik çevresel bozulma göstergelerinin birleştirilerek toplam gösterge halinde değerlendirilmesi kaynak verimliliğini arttırmada daha sağlıklı sonuçların ortaya çıkmasını sağlayacaktır. Bu bağlamda, ayak izi, insan faaliyetlerinin yükünü ve küresel sürdürülebilirlik üzerindeki etkilerini ifade etmenin popüler bir yolu olarak karşımıza çıkmaktadır. Karbon, su, emisyon, enerji, azot, biyolojik çeşitlilik, fosfor, atık, sosyal, finansal, ekonomik, ekserji, kimyasal ve ekolojik ayak izi (EF) gibi birçok ayak izi bulunmaktadır (Cucek vd., 2012: 10-13). EF başlangiçta Rees (1992) tarafindan önerilmiş, Wachernagel ve Rees (1996) tarafından geliştirilmiş ve insanlığın doğaya yönelik taleplerinin birincil ölçümü olarak ortaya çıkmıştır. Günümüzde de çevresel sürdürülebilirliği ölçmek için yaygın bir gösterge olarak kullanılmaktadır. Toprak ve su alanlarına yönelik insan talebinin bir ölçüsü olarak tanımlanan $\mathrm{EF}$, kaynakların tüketimi ve atıkların emilimini Dünya'nın ekolojik kapasitesi ile karşılaştırır. Bu şekilde EF çeşitli insani faaliyetleri takip ederek $\mathrm{CO}_{2}$ emisyonları, balık tüketimi, arazi kullanımı gibi antropojenik basınçların birleşik etkisini izleyebilmekte ve çevresel sonuçları anlamak için kullanılabilmektedir (Galli vd., 2012: 102). EF ekili araziler, otlak arazileri, orman ürünleri, balıkçılık sahaları, inşa edilmiş araziler ve karbon ayak izi olmak üzere altı bileşenden oluşmaktadır (Ulucak ve Bilgili, 2018: 145). Karbon ayak izi altı bileşen içerisinde en fazla paya sahiptir ve EF'nin yarısından 
fazlasını oluşturmaktadır. Bu yüzden sera gazı emisyonları EF bileşenleri arasında yer almaktadır. Doğal kaynaklara veya doğal sermayeye olan talep EF olarak adlandırılırken bu kaynakların veya sermayenin arzı ise biyokapasite (BC) olarak tanımlanmaktadır. Doğal kaynakların BC'leri sürdürülebilir bir yaşam alanının olması için EF'ye eşit veya EF'den büyük olması gerekmektedir. BC, EF'den büyük olduğu durumda biyolojik açık, tersi durumda ekolojik açık meydana gelir. Tüm dünyada 1970'li yıllardan itibaren EF, BC'yi aşmaya başlamış ve aradaki açık giderek artmaya devam etmiştir. $\mathrm{Bu}$ durum da sürdürülebilir yaşam alanlarının azalmasına sebebiyet vermektedir.

Belli başlı ülkelerde veya ülke gruplarında çevre kirliliği giderek artmaktadır. Ağır sanayi, kentleşme, endüstrileşme gibi faktörler çevresel tahribata neden olmaktadır. Gelecek 11 olarak adlandırılan ve hızlı ekonomik büyümeye sahip N11 ülkeleri de Güney Kore haricinde, gelişmekte veya yeni sanayileşen ülkelerden (Türkiye, Bangladeş, Mısır, Endonezya, İran, Meksika, Nijerya, Pakistan, Filipinler ve Vietnam) oluşmaktadır. Dolayısıyla bu ülkelerde hızlı ekonomik büyüme faaliyetleriyle birlikte ağır sanayi yoğun olarak kullanılmaktadır ve bu durum kapsamlı bir gösterge olan EF'de artışa sebebiyet vermektedir. Şekil 1'de N11 ülkelerinde 1971-2016 döneminde meydana gelen EF ile BC verileri yer almaktadır. Şekilde mavi ve kahverengi çizgiler sırasıyla BC ve EF'yi göstermektedir. 1973 yılına kadar BC, EF'den fazla iken bu yıldan sonra iki gösterge arasındaki ekolojik açık giderek açılmaya başlamıştır. 1971 yılında 12,70 küresel hektar olan EF, 2016 yılına gelindiğinde yaklaşı \%96 artarak 24,87 küresel alana ulaşmıştır. BC ise aynı dönem aralığında \%37'lik bir azalışla 13,88 küresel alandan 8,77 küresel alana düşmüştür. $\mathrm{Bu}$ durum gelişmekte olan ve yeni sanayileşen N11 ülkelerinde aşırı çevresel zararlar neticesinde sürdürülebilir yaşam alanlarının giderek azaldığını gözler önüne sermektedir. Bu yüzden ilgili ülke grubunda EF'nin stokastik özelliklerini araştırmak ve yorumlamak büyük bir önem arz etmektedir.

Şekil 1: N11 Ülkelerinde EF ve BC’nin Karşılaştırılması

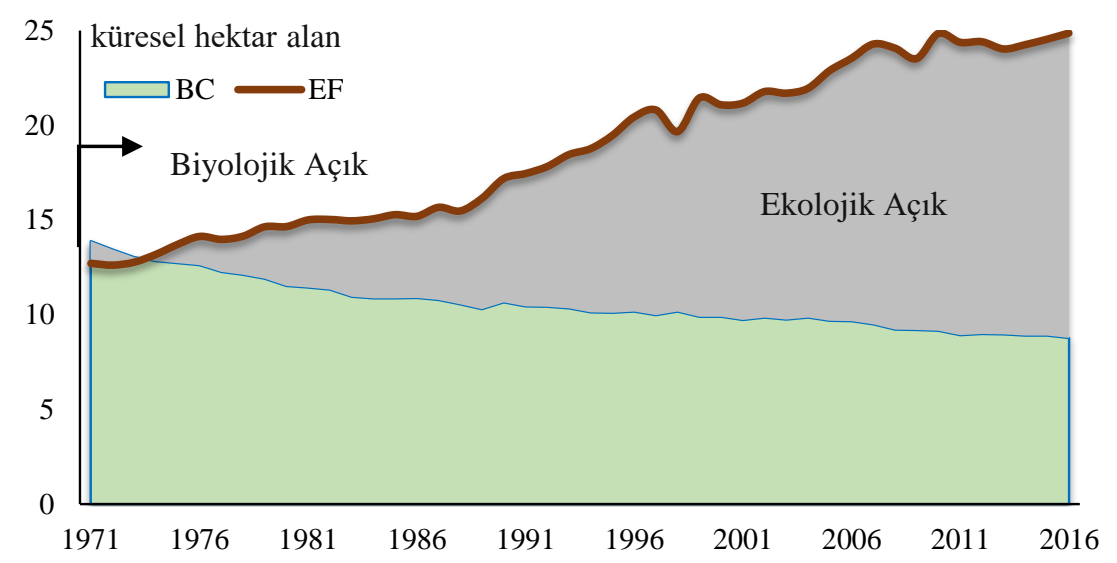

Kaynak: https://www.footprintnetwork.org/ 
Beş bölümden oluşan ve N11 ülkelerinde EF'nin çevre üzerinde etkilerinin geçici mi yoksa kalıcı mı olduğunu araştıran bu çalışmada giriş bölümünü takiben ikinci bölümde EF'nin durağanlığını test eden çalışmalara ait literatür özeti bulunmaktadır. Üçüncü bölümde veri seti ve metodolojiden bahsedilirken, dördüncü bölümde kullanılan yöntemler neticesinde elde edilen ampirik sonuçlara yer verilmiştir. Beşinci bölümde ise sonuç kısmı yer almaktadır.

\section{Literatür}

Çevre ekonomisi literatüründe son yıllarda üç ana araştırma konusu olmuştur (Yilanci vd., 2019: 270). Bunlardan birincisi çevresel Kuznets eğrisi (ÇKE) hipotezidir. Panayotou (1993), Kuznets (1955)'in yapmış olduğu çalışmadan esinlenerek, çevre kirliliği ile ekonomik büyüme arasındaki ilişkiyi gösteren eğriye çevresel Kuznets eğrisi adını vermiştir. İlerleyen yıllarda da ÇKE hipotezi ile alakalı birçok çalışma gerçekleştirilmiştir (Jalil ve Mahmud, 2008; Shafiei ve Salim, 2014; Onater-Isberk, 2016; Pata ve Yurtkuran, 2018). ÇKE hipotezi; ekonominin ilk gelişim sürecinde ağır sanayi faaliyetleriyle birlikte gelir düzeyi arttıkça çevre kirliliğinin belirli bir noktaya kadar artacağını, bu noktadan sonra gelir düzeyindeki artış devam ettikçe toplumların çevre konusunda bilinçleneceğini ve temiz çevreye olan talebin artacağını varsaymaktadır. $\mathrm{Bu}$ durumda da çevre kirliliğinde azalış yaşanacağı belirtilmektedir. İkincisi kirlilik sı̆̆ınağı hipotezi (KSH)'dir. Bu hipoteze göre, gelişmiş ülkelerde çevre vergisinin, düzenlemelerinin ve standartlarının daha katı olduğu varsayılmaktadır. Bu yüzden gelişmiş ülkelerin, gelişmekte olan ülkelere sermayelerini taşımaları sonucunda ev sahibi ülkede çevre kirliliği artmaktadır. Bu vd. (2013), Solarin vd. (2017), Zheng ve Shi (2017) ve Shen vd. (2019) yapmış oldukları çalışmada KSH'nin geçerli olduğu sonucuna ulaşmışlardır. Üçüncüsü, durağanlık analizidir. Bu analizler, serilerde meydana gelen şokların kalıcı mı yoksa geçici mi olduğunu belirlemek için ampirik araştırmalarda yaygın olarak kullanılmaktadır. Literatürde çeşitli çevresel göstergeler kullanılarak yapılan çalışmalar bulunmaktadır.

Durağanlık analizlerinde List (1999) sülfürdioksit ve nitrojenoksit $\left(\mathrm{NO}_{2}\right)$; Carrioni Silvestre vd. (2009), Sidneva ve Zivot (2014) ve Gil-Alana ve Solarin (2018) $\mathrm{NO}_{2}$ ve uçucu organik bileşenleri çevresel gösterge olarak kullanmışlardır. $\mathrm{Bu}$ testlerde çevresel gösterge olarak en fazla kullanılan değişken $\mathrm{CO}_{2}$ emisyonudur. Heil ve Selden (1999) 1950-1992 döneminde 135 ülkede yapmış olduğu analizde 20 ülkede serilerin birim kök içerdiği sonucuna ulaşmışlardır. List ve Strazicich (2003) 1960-1997 döneminde sanayileşmiş 21 ülkede hem yatay kesit hem de zaman serisi analizleriyle gerçekleştirmiş oldukları çalışmada $\mathrm{CO}_{2}$ emisyonunun durağan olduğunu belirlemişlerdir. Stegman (2005) 1950-1999 döneminde 97 ülkede bölüşüm analizi ile yapmış oldukları çalışmada 26 ülkede mutlak anlamda durağanlığa ait küçük kanıtlar tespit etmiştir. Panopoulou ve Pantelidis (2007) 1960-2003 döneminde 128 ülkede panel veri analiziyle gerçekleştirmiş oldukları çalışmada $\mathrm{CO}_{2}$ emisyonu değişkeninin durağan olduğu sonucuna ulaşmışlardır. Lee ve Chang (2009) 1950-2002 döneminde 21 OECD ülkesi için panel birim kök 
testiyle yapmış oldukları çalışmada yapısal kırılmalardan sonra $\mathrm{CO}_{2}$ emisyonunun durağan olduğunu tespit etmişlerdir. Tiwari vd. (2016) 1960-2009 döneminde 35 Sahra Altı Afrika ülkesinde gerçekleştirmiş oldukları analizde 15 ülkede $\mathrm{CO}_{2}$ emisyonu değişkeninin durağan olduğunu belirtmişlerdir. Gil-Alana vd. (2017) çeşitli tarihlerde G7 (ABD, İngiltere, Japonya, Kanada, Almanya, Fransa ve İtalya) ve BRICS (Brezilya, Rusya, Hindistan, Çin ve Güney Afrika) ülkelerinde $\mathrm{CO}_{2}$ emisyonunun durağanlığı test etmiştir. Yazarlar Almanya, Amerika ve İngiltere'de ilgili değişkenin durağan olduğunu belirlemişlerdir. Cai vd. (2018) 1950-2014 döneminde 21 OECD ülkesinde Fourier kantil birim kök testiyle $\mathrm{CO}_{2}$ emisyonunun durağanlığını incelemişlerdir. Yazarlar Kanada, Finlandiya, Hollanda, Portekiz, İspanya, İsviçre ve İngiltere'de düşük kantil tespit etmişlerdir.

$\mathrm{Bu}$ çalışmada EF göstergesinin durağan olup olmadığ Dolayısıyla EF göstergesine ait elde edilen sonuç birim kök içerirse çevre konularını içeren politikaların şok etkisi kalıcı, durağan olursa geçici olmaktadır. Son yıllarda ekolojik gösterge olarak EF değişkenine ait yapılan ampirik analizler kullanılmaya başlanmıştır. Bu yüzden bu değişkenin durağanlık testleri oldukça azdır. EF değişkeninin durağanlığının test edildiği çalışmalardan Ulucak ve Apergis (2018) 1961-2013 döneminde 20 AB ülkesinde Phillips-Sul kulüp yakınsama testi ile yapmış oldukları analizde az sayıda kulüp yakınsaması olduğu sonucuna ulaşmışlardır. Yilanci vd. (2019) 1961-2013 döneminde 25 OECD ülkesinde panel Fourier durağanlık testiyle gerçekleştirmiş oldukları çalışmada EF'nin altı bileşenini analize dahil etmişlerdir. Yazarlar balıkçılık sahaları değişkeninde rraksama, diğer değişkenlerde yakınsama olduğunu belirtmişleridir. Solarin ve Bello (2018) 1961-2013 döneminde 128 ülkede yapmış oldukları analizde 96 ülkede EF serisinin birim kök içerdiğini tespit etmişler ve bu ülkelerde uygulanan çevresel politikaların EF üzerinde kalıcı şok etkisi yaptığını belirtmişlerdir. Bilgili ve Ulucak (2018) 1961-2014 döneminde G20 ülkelerinde panel KPSS birim kök testi yardımıyla gerçekleştirmiş olduğu çalışmada stokastik ve deterministik durağanlıkların gerçekleştiğini tespit etmişlerdir. Solarin vd. (2019) 1961-2014 döneminde 93 ülkede yapmış oldukları çalışmada iki kulüp yakınsama yaklaşımını uygulamışlardır ve EF için 10, yapılaşmış alan ayak izi için de 4 yakınsayan kulüp olduğunu belirlemişlerdir. Solarin (2019) 1961-2013 döneminde 27 OECD ülkesinde RALS-LM birim kök testi ile gerçekleştirmiş olduğu çalışmada 13 ülkede serilerin durağan olduğu, 12 ülkede ise birim kök içerdiği sonucuna ulaşmıştır. Bilgili vd. (2019) 1961-2014 döneminde 60 ülkede Panel KPSS birim kök testi yardımıyla yapmış oldukları analizde Afrika, Amerika ve Avrupa'da yakınsama, Asya'da ise iraksama olduğunu tespit etmişlerdir. Ozcan vd. (2019) 1961-2013 döneminde üst, orta-üst, orta-düşük ve düşük gelir düzeyli olmak üzere dört ülke grubu için panel birim kök testleri yardımıyla gerçekleştirmiş olduğu analizde yüksek gelirli ülkelerde yakınsama, düşük ve üstorta gelirli ülkelerin yarısında ise yakınsama olduğu sonucuna ulaşmışlardır.

Birçok çalışmada çevre kirliliğinin göstergesi olarak durağanlık testinde $\mathrm{CO}_{2}$ emisyonu kullanılmıştır. Çok az çalışmada da bu gösterge için EF değişkeninden 
yararlanılmıştır. EF birçok değişkeni içerisine aldığ 1 için $\mathrm{CO}_{2}$ emisyonuna göre daha kapsamlı bir göstergedir. Bu yüzden çevre kirliliği göstergesi olarak bu çalışmada EF'yi analize dahil etmek sonuçların daha sağlıklı çıkmasını sağlayacaktır. Ayrıca literatürde gerçekleştirilen çalışmalara bakıldığında N11 ülkeleri için EF üzerinde meydana gelen şokların etkisinin kalıcı mı yoksa geçici mi olduğunu tespit eden çalışma bulunmamaktadır. Dolayısıyla bu çalışmanın bu anlamda bir ilk olarak literatüre katkı sağlaması amaçlanmaktadır.

\section{Veri Seti ve Metodoloji}

\subsection{Veri Seti}

Bu çalışmada N11 ülkeleri için ekolojik ayak izi yakınsaması test edilmektedir. EF kişi başına düşen ekolojik ayak izini temsil etmektedir. Veriler http://data.footprintnetwork.org/\#/ adresinden derlenmiştir. Bangladeş'e ait veriler 1971 yılından başladığı için çalışma dönemi 1971-2016 olarak belirlenmiştir.

\subsection{Metodoloji}

\subsubsection{Yatay Kesit Bağımlılığı ve Homojenlik Testleri}

Seriler arasında yatay kesit bağımlılığı olup olmadığını belirlemek, birim kök testlerinde elde edilecek sonuçlara büyük bir etki oluşturmaktadır. Serilerin analiz sürecine geçmeden önce yatay kesit bağımlılığının belirlenmesi gerekmektedir. $\mathrm{Bu}$ test yapılmadan uygulanan analizler hatalı sonuçların çıkmasına sebebiyet verebilmektedir.

Panel veri analizlerinde bir ülkede ortaya çıkan şoklar diğer ülke veya ülkelerde de şok etkisi oluşturabilmektedir. Bu duruma yatay kesit bağımlılığı adı verilmektedir. Ülkeler arasında yatay kesit bağımlılığının olup olmadığının tespitinde öncü çalışma Breusch ve Pagan (1980)'ın yapmış olduğu LM testidir. $\mathrm{Bu}$ testten sonra çeşitli çalışmalar gerçekleştirilmiş ve değişik şekillerde yatay kesit bağımlılığı sınanmıştır. Pesaran (2004) ve Pesaran, Ullah ve Yamagata (2008) sırasıyla CD, CD $\mathrm{LM}_{\mathrm{LM}}$ ve düzeltilmiş LM testlerini geliştirmişler ve ülkeler arasında meydana gelen şokların birbirleri üzerinde etkisi olup olmadığını araştırmışlardır.

$\mathrm{CD}, \mathrm{CD}_{\mathrm{LM}}$ ve düzeltilmiş $\mathrm{LM}$ testlerinde, kesit sayısı ve zaman boyutu az olduğunda daha sağlıklı sonuçlara ulaşılabilmektedir. Yatay kesit bağımlılı̆̆ için geliştirilen bu testlerin içerisinde en sağl1klı sonuçlar LM testiyle elde edilmektedir. Dört test için de $\mathrm{H}_{0}$ hipotezi ülkeler arasında herhangi bir yatay kesit bağımlılığı olmadığını ifade ederken, alternatif hipotez bir ülke veya ülke grubunda gerçekleşen şokların diğer ülkeleri de etkileyebileceğini belirtmektedir.

Panel veri yönteminde analize dahil olan ülkelerin karakteristik özellikleri benzerlik taşıyabilmektedir. Böyle bir durum söz konusu ise ülkeler homojen, değilse heterojen bir yapıya sahip olmaktadır. Ülkeler arasındaki ilişkide homojenlik veya heterojenlik durumunu tespit etmek için delta $(\widetilde{\Delta})$ veya 
düzeltilmiş delta $\left(\widetilde{\Delta}_{\text {adj }}\right)$ testleri kullanılmaktadır. Bu iki test sırasıyla Swamy (1970) ve Pesaran ve Yamagata (2008) tarafından geliştirilmiştir. Bu testlerde $\mathrm{H}_{0}$ hipotezi paneldeki ülke gruplarının homojen, alternatif hipotez ise heterojen bir yapıya sahip olduklarını ifade etmektedir.

\subsubsection{Yatay Kesitsel Genişletilmiş Dickey-Fuller Birim Kök Testi}

Belirli bir süreç içerisinde ortaya çıkan şokların etkisinin kalıcı mı veya geçici mi olduğunu tespit etmek için birim kök veya durağanlık testleri kullanılmaktadır. Seriler birim kök içermezse şoklar geçici olmaktadır. Bu testlerden bazıları yatay kesit bağımlılığını dikkate almaktadır. Pesaran (2007) tarafından geliştirilen ve yatay kesit bağımlılığını dikkate alan Yatay Kesitsel Genişletilmiş Dickey-Fuller birim kök testi (CADF) ile değişkenlerin durağanlık dereceleri tespit edilebilmektedir. $\mathrm{Bu}$ birim kök testine ait kurulan model denklem 1'de gösterilmektedir.

$\Delta \mathrm{S}_{\mathrm{it}}=\delta_{\mathrm{i}}+\beta_{\mathrm{i}} \mathrm{S}_{\mathrm{it}-1}+\alpha_{\mathrm{i}} \overline{\mathrm{S}}_{\mathrm{t}-1}+\sum_{\mathrm{j}=0}^{1} \varphi_{\mathrm{ij}} \Delta \overline{\mathrm{S}}_{\mathrm{it}-1}+\sum_{\mathrm{j}=0}^{1} \varphi_{\mathrm{ij}} \mathrm{S}_{\mathrm{it}-1}+\mathrm{u}_{\mathrm{it}}$

Denklem 1'de her bir birim için değişkenlerin ortalama değerleri $\overline{\mathrm{S}}_{\mathrm{t}}$ ile ifade edilmektedir. Değişkenler birim kök içeriyorsa $\beta_{i}$ katsayısı sıfıra eşit olmakta, durağan ise bu katsayı sıfırdan farklı bir değer almaktadır. CADF testinde sıfır hipotezi serilerin birim kök içerdiğini, alternatif hipotez ise durağan olduğunu belirtmektedir. $\mathrm{Bu}$ testte serilerin birim kök içerip içermediğinin tespitinde Pesaran (2007) tablo kritik değerleri kullanılmaktadır.

\subsubsection{Fourier Panel Birim Kök Testi}

Geleneksel birim kök testleri arasında yer alan Genişletilmiş-Dickey-Fuller (ADF) (1981), Phillips-Perron (PP) (1988), Kwiatkowski, Phillips, Schmidt ve Shin (KPSS) (1992) ve Dickey-Fuller genelleştirilmiş en küçük kareler (DF-GLS) (1996) testlerinde yapısal kırılmalar göz ardı edilmektedir. Analize dahil edilen değişkenler başta ekonomik kriz, arz ve talep şokları gibi belli başlı makroekonomik değişimlerin etkisi altında kalabilmektedir. İncelenen seri belirlenirken yapısal değişimlerin etkisi altında kalıp kalmadığı dikkate alınmalıdır. Bu yüzden makroekonomik değişimler dikkate alınmadan geleneksel birim kök testleri ile gerçekleştirilen çalışmaların sonuçları tartışmaya açık ve sağlıksız olabilmektedir.

Yapısal kırılmalar ilk olarak Perron (1989) tarafından analize dışsal bir değişken olarak eklenmiştir ve bu testte tek yapısal kırılmaya izin verilmiştir. Bu testle birlikte birim kök testleri analizlerinde yeni bir süreç başlamıştır. Zivot ve Andrews (1992), Perron (1989) gibi birim kök testi analizinde tek yapısal kırılmaya izin vermiş; ancak bu yapısal kırılmayı modelin içerisine almıştır. Lumsdaine ve Papell (1997) ve Lee ve Strazicich (2003) ise modelin içerisinde 
yer alan ve iki yapısal kırılmayı tahmin edebilen birim kök testi geliştirmişlerdir. Ancak bu testlerde yapısal kırılmalar sert geçişli olmakta ve sayısı önceden belirlenebilmektedir. Yani iki yapısal kırılmaya sahip bir seriye Zivot ve Andrews (1992) birim kök testini uygulamak veya yapısal kırılmaya sahip olmayan bir seriye Lee ve Strazicich (2003) birim kök testini koşturmak sonuçların hatalı ve tutarsız çıkmasına neden olabilmektedir. Bunun yanında sert geçişli birim kök testleriyle analiz yapmak yumuşak geçişlerin ve ortaya çıkabilecek kısa süreli yapısal değişimlerin etkilerinin ihmaline sebebiyet verebilmektedir.

Becker, Enders ve Lee (2006) bahsi geçen problemleri ortadan kaldırmak için Gallant (1981) tarafından geliştirilmiş Fourier fonksiyonlarını KPSS birim kök testine ilave etmişler ve Fourier-KPSS (FKPSS) durağanlık testini geliştirmişlerdir. $\mathrm{Bu}$ testte yumuşak geçişlerin sayısı, zamanı ve yapısı belli olmamaktadır. FKPSS durağanlık testinde birikimli frekanslı Fourier fonksiyonları denklem 2'de, tek frekanslı Fourier fonksiyonları da denklem 3'te gösterilmektedir.

$$
\begin{aligned}
& \alpha(\mathrm{t}) \cong \varphi_{0}+\sum_{\mathrm{k}=1}^{\mathrm{n}} \delta_{1, \mathrm{i}} \sin \left(\frac{2 \pi \mathrm{k}_{\mathrm{i}} \mathrm{t}}{\mathrm{T}}\right)+\sum_{\mathrm{k}=1}^{\mathrm{n}} \eta_{2, \mathrm{i}} \cos \left(\frac{2 \pi \mathrm{k}_{\mathrm{i}} \mathrm{t}}{\mathrm{T}}\right) \\
& \alpha(\mathrm{t}) \cong \varphi_{0}+\beta_{1, \mathrm{i}} \sin \left(\frac{2 \pi \mathrm{kt}}{\mathrm{T}}\right)+\theta_{2, \mathrm{i}} \cos \left(\frac{2 \pi \mathrm{kt}}{\mathrm{T}}\right)
\end{aligned}
$$

Denklem 2'de deterministik terim $\alpha(\mathrm{t})$, gözlem sayısı T, T/2'den az olan frekans sayısı n, belirli bir frekans k ile temsil edilmektedir. Katsayılar ise $\delta_{1, \tilde{i}}, \eta_{2, \mathfrak{i}}, \beta_{1, \tilde{i}}$ ve $\theta_{2, \mathrm{i}}$ ile ifade edilmektedir. Denklem 3 'te ise $\mathrm{n}=1$ olduğu için toplam fonksiyonları modele eklenmemiştir.

Carrion-i-Silvestre, Del Barrio-Castro ve López-Bazo (2005)'nun geliştirmiş oldukları CBL birim kök testi KPSS yöntemine dayanmakta, yatay kesitlerin her biri için durağanlık hakkında bilgi içermekte ve sert geçişlere imkan tanımaktadır. $\mathrm{Bu}$ test ayrıca panel verilerde yatay kesit bağımlılığını dikkate almaktadır. CBL birim kök testinde KPSS testinde olduğu gibi $\mathrm{H}_{0}$ hipotezi geçerli olduğu durumda seriler durağan olmaktadır. CBL durağanlık yöntemi için kurulan model denklem 4 'te ifade edilmektedir.

$y_{i, t}=\alpha_{i}+\sum_{k=1}^{m_{i}} \delta_{i, k} D U_{i, k, t}+e_{i, t}$

Sabitli model için kurulan denklem 4'te optimal yapısal kırılma sayısı m, sabit terim $\alpha_{i}$, sert geçişler DU kukla değişkeni ile temsil edilmektedir. DU kukla değişkeni iki farklı durumda değer almaktadır. Bu durum denklem 5'te ifade edilmektedir. 
$\mathrm{t}>\mathrm{TB}_{\mathrm{k}}$ durumunda 1 , diğer durumlarda 0

Denklem 4'te $\mathrm{TB}_{\mathrm{k}}$, $\mathrm{k}$ tarihinde gerçekleşen kırılmayı temsil etmektedir. $\delta_{\mathrm{i}, \mathrm{k}}$ ise yatay kesit verilerinin her bir kesitinde ortaya çıkan farklı etkileri ifade etmektedir. Bu testte yapısal kırılmalar belirlenirken her bir yatay kesit verisi farklı sayıda ve tarihte olabilmektedir. Bu yüzden $\mathrm{CBL}$ durağanlık yönteminde seriler arasında heterojenlik varsayımının geçerli olması gerekmektedir (Ozcan ve Ozturk, 2016: 335).

Bahmani-Oskooee, Chang ve Wu $(2014,2015)$ panel CBL birim kök testine Fourier fonksiyonlarını eklemiş ve sert kırılma tarihlerinin yanına yumuşak geçişlere de izin veren yeni bir birim kök testi geliştirmişlerdir. Bu testin birtakım avantajı bulunmaktadır. Birincisi panel Fourier CBL birim kök testi heterojenliğe ve yatay kesit bağımlılı̆̆ına izin vermektedir. İkincisi yapısal kırılmaların belirlenmesinde tarihine, yapısına ve sayısına bakılmasına gerek duyulmamaktadır. Denklem 3'teki tek frekanslı FKPSS testine ait model ile denklem 4'teki CBL testine ait model birleştirilerek Fourier-CBL birim kök testi oluşturulmuştur. Bu teste ait kurulan model denklem 6'da gösterilmektedir.

$\mathrm{y}_{\mathrm{i}, \mathrm{t}}=\delta_{\mathrm{i}}+\sum_{\mathrm{k}=1}^{p_{\mathrm{i}}} \beta_{\mathrm{i}, \mathrm{k}} \mathrm{D} \mathrm{U}_{\mathrm{i}, \mathrm{k}, \mathrm{t}}+\varphi_{1, \mathrm{i}} \sin \left(\frac{2 \pi k \mathrm{t}}{\mathrm{T}}\right)+\varphi_{2, \mathrm{i}} \cos \left(\frac{2 \pi k \mathrm{t}}{\mathrm{T}}\right)+\mathrm{w}_{\mathrm{i}, \mathrm{t}}$

Denklem 2'de yer alan kümülatif bileşenler kullanıldığı taktirde serbestlik derecesi azalmakta ve yüksek varyans sorunu ortaya çıkmaktadır (Enders ve Lee, 2012: 197). Denklem 3'te yer alan tek frekansa sahip bileşenlerin kullanılması bu problemi ortadan kaldırabilir. Bu yüzden bu çalışmada tek frekansa sahip Fourier fonksiyonlarından yararlanılmıştır. Denklem 6'da yer alan değerlerden gözlem sayısı $\mathrm{T}$, yapısal kırılma tarihleri $\mathrm{p}$, frekanslar $\mathrm{k}$ ile gösterilmektedir. Keskin kırılma tarihlerinin elde edildiği kukla değişkenler DU ile ifade edilirken, yumuşak geçişlerin yakalandığı katsayılar $\varphi_{1}$ ve $\varphi_{2}$ ile temsil edilmektedir. Kukla değişkenler CBL birim kök testinde olduğu gibi iki duruma göre farklı değerler almaktadır. $\mathrm{TB}_{\mathrm{k}-1}^{\mathrm{i}}<\mathrm{t}$ olduğu durumda kukla değişkenler $1, \mathrm{t}<\mathrm{TB}_{\mathrm{k}}^{\mathrm{i}}$ durumunda 0 değerini almaktadır.

İki aşamaya sahip Fourier-CBL durağanlık testinin ilk aşamasında keskin kırılma tarihleri $(\mathrm{m})$ belirlenmekte ve optimal frekans $(\mathrm{k})$ tespit edilmektedir. Testin ikinci aşamasında ise doğrusal olmayan bileşenlerin denkleme dahil edilip edilmeyeceği belirlenmektedir. Bu durum denklem 7 yardımıyla sınanmaktadır.

$$
\mathrm{F}\left(\mathrm{k}^{*}\right)=\frac{\left(\mathrm{KKT}_{0}-\mathrm{KKT}_{1}\left(\mathrm{k}^{*}\right)\right) / 2}{\mathrm{KKT}_{1}\left(\mathrm{k}^{*}\right)(\mathrm{T}-\mathrm{q})}
$$

Denklem 7'de kisitsiz ve kisitlı kareler toplamı sirasiyla $\mathrm{KTT}_{0}$ ve $\mathrm{KTT}_{1}$ ile gösterilmektedir. Keskin kırılma tarihleri (m) tespit edildikten sonra optimal 
frekans (k) belirlenmektedir. Minimum KTT değerini veren $\mathrm{k}^{*}$ belirlendikten sonra denklem 6' da $\mathrm{K}=\mathrm{k}^{*}$ olacak şekilde yeniden tahmin gerçekleştirilmektedir. Elde edilen $\mathrm{KKT}_{0}$ ve $\mathrm{KTT}_{1}$ değerlerinden sonra denklem 7 tahmin edilerek Fistatistik değeri hesaplanmaktadır. Alternatif hipotezine göre bulunan F-istatistik değeri tablo kritik değerinden büyük olmakta ve doğrusal olmayan trigonometrik terimlerin modele dahil edilmesi uygun görülmektedir. $\mathrm{H}_{0}$ hipotezinin geçerli olduğu durumda ise doğrusal olmayan trigonometrik terimlerin modele dahil edilmesi uygun görülmemekte ve doğrusal yapıya sahip durağanlık testlerinin uygulanmasının daha sağlıklı sonuçlar vereceği öngörülmektedir. Fourier-CBL durağanlık testinde yokluk hipotezi serilerin keskin, yumuşak, bilinen ve bilinmeyen yapısal kırılmalarla birlikte durağan bir yapıya sahip olduğunu belirtmektedir.

\section{Ampirik Sonuçlar}

Yatay kesit bağımlılığı ve homojenlik testi sonuçları tablo 2'de gösterilmektedir. $\mathrm{LM}, \mathrm{CD}_{\mathrm{LM}}, \mathrm{CD}$ ve $\mathrm{LM}_{\mathrm{adj}}$ testlerine göre serilerin hepsi \%1 seviyesinde anlamlı çıkmıştır ve $\mathrm{H}_{0}$ hipotezi reddedilmiştir. $\mathrm{Bu}$ durum seriler arasında yatay kesit bağımlılığının geçerli olduğunu göstermektedir. Yani bu testler ile gelişmekte ve yeni sanayileşmekte olan N11 ülkeleri arasında etkileşim olduğu sonucuna ulaşılmaktadır. Homojenlik testi sonuçları da $\widehat{\Delta}$ ve $\bar{\Delta}_{\text {adj }}$ yöntemleri ile belirlenmiştir. Elde edilen sonuçlara bakıldığında $\mathrm{H}_{0}$ hipotezinin reddedildiği ve serilerin heterojen bir yapıya sahip olduğu belirlenmiştir. Bu yüzden bu çalışmada yatay kesit bağımlılı̆g kullanılmıştır.

Tablo 2: Yatay Kesit Bağımlılığı ve Homojenlik Testleri

\begin{tabular}{|l|c|c|c|c|c|c|}
\hline Testler & $\mathbf{L M}$ & $\mathbf{C D}_{\mathbf{L M}}$ & $\mathbf{C D}$ & $\mathbf{L M}_{\mathbf{a d j}}$ & $\widehat{\Delta}$ & $\widehat{\Delta}_{\text {adj }}$ \\
\hline $\begin{array}{l}\text { Test } \\
\text { istatistiği }\end{array}$ & 83,481 & 2,716 & $-3,017$ & 163,283 & 3,942 & 4,078 \\
\hline $\begin{array}{l}\text { Olasılık } \\
\text { değeri }\end{array}$ & 0,008 & 0,003 & 0,001 & 0,000 & 0,000 & 0,000 \\
\hline
\end{tabular}

İlk başta Fourier-CBL birim kök testinde kullanılan doğrusal olmayan trigonometrik terimlerin analize dahil edilmesine karar vermek için F-istatistik testi yapılmış ve optimal frekanslar belirlenmiştir.

F-istatistik testi sonuçları tablo 3'te gösterilmektedir. Uygun frekans değerleri Bangladeş, İran, Güney Kore ve Nijerya için bir; Türkiye ve Filipinler için iki; Mısır için üç; Endonezya için dört; Meksika ve Pakistan için beş olarak belirlenmiştir. F-istatistik değerleri Vietnam dişında bütün ülkelerde anlamlı çıkmıştır. Bu yüzden bu çalışmada durağanlık testi uygulanırken doğrusal olmayan terimlere izin veren Fourier-CBL durağanlık testinin yanında yalnızca doğrusal terimlerin yer aldığı CADF birim kök testi de kullanılmıştır. 
Trigonometrik terimlerin analize dahil edilmesiyle yumuşak geçişlere de izin verilmektedir.

Tablo 3: Uygun Frekans Seçimi ve F-istatistiği

\begin{tabular}{|l|c|c|c|c|c|}
\hline Ülkeler & F-istatistiği & $\mathbf{\% 1}$ & $\mathbf{\% 5}$ & $\mathbf{\% 1 0}$ & $\begin{array}{c}\text { Uygun } \\
\text { Frekans }\end{array}$ \\
\hline Türkiye & $17,7245 * * *$ & 5,316 & 3,3331 & 2,4653 & 2 \\
\hline Bangladeş & $247,8802 * * *$ & 5,2462 & 3,3106 & 2,4878 & 1 \\
\hline Misır & $17,0459^{* * *}$ & 5,555 & 3,3278 & 2,4893 & 3 \\
\hline Endonezya & $31,5669 * * *$ & 5,53 & 3,3588 & 2,5542 & 4 \\
\hline İran & $95,9338^{* * *}$ & 5,6197 & 3,4688 & 2,6246 & 1 \\
\hline Güney Kore & $8,3296^{* * *}$ & 5,344 & 3,348 & 2,5182 & 1 \\
\hline Meksika & $12,8154 * * *$ & 5,1074 & 3,2603 & 2,4132 & 5 \\
\hline Nijerya & $51,7655^{* * *}$ & 5,4065 & 3,3851 & 2,573 & 1 \\
\hline Pakistan & $14,5624 * * *$ & 5,1661 & 3,2487 & 2,417 & 5 \\
\hline Filipinler & $28,5091 * * *$ & 4,8926 & 3,0498 & 2,2951 & 2 \\
\hline Vietnam & 1,0864 & 5,2667 & 3,3124 & 2,5096 & 2 \\
\hline
\end{tabular}

Not: Uygun frekansların belirlenmesinde en küçük KKT’ye yöntemi kullanılmıştır. *** \%1'de anlamli.

F-istatistik testiyle uygun frekanslar belirlendikten sonra yapısal kırılma tarihleri tespit edilmiştir. Tablo 4'teki sonuçlara göre İran ve Vietnam'da beş; Bangladeş, Misır, Endonezya, Güney Kore, Nijerya ve Pakistan'da dört; Türkiye'de üç; Meksika'da iki ve Filipinler'de bir yapısal kırılma gerçekleşmiştir. 1974'ten itibaren N11 ülkelerinde ekolojik açık başlamış ve bu yıllarda ilgili ülke gruplarının birçoğunda yapısal kırılmalar gerçekleşmiştir.

Tablo 4: Keskin Kırılma Tarihleri

\begin{tabular}{|l|c|c|c|c|c|}
\hline Ülkeler & TB $_{1}$ & $\mathbf{T B}_{\mathbf{2}}$ & $\mathbf{T B}_{\mathbf{3}}$ & $\mathbf{T B}_{4}$ & $\mathbf{T B}_{\mathbf{5}}$ \\
\hline Türkiye & 1974 & 1994 & 2004 & - & - \\
\hline Bangladeș & 1979 & 1984 & 1988 & 1995 & - \\
\hline Misır & 1974 & 1982 & 1996 & 2004 & - \\
\hline Endonezya & 1985 & 1994 & 2007 & 2011 & - \\
\hline İran & 1974 & 1979 & 1983 & 1997 & 2008 \\
\hline Güney Kore & 1975 & 1989 & 2000 & 2009 & - \\
\hline Meksika & 1974 & 1993 & - & - & - \\
\hline Nijerya & 1977 & 1983 & 2002 & 2006 & - \\
\hline Pakistan & 1984 & 1992 & 2003 & 2009 & - \\
\hline Filipinler & 1988 & - & - & - & - \\
\hline Vietnam & 1994 & 1999 & 2003 & 2007 & 2012 \\
\hline
\end{tabular}

Not: Maksimum kırılma sayısı 5 olarak belirlenmiştir. TB: Kırılma tarihini göstermektedir. 
Yapısal kırılma tarihleri tespit edilen serilerin gerçekleşen ve tahmini zaman yolları oluşturulmuştur. Trigonometrik terimler ile serilerin birlikte hareketi her bir ülke için Şekil 1'de gösterilmektedir.

Şekil 1: Serilerin Tahmin Edilen ve Gerçekleşen Zaman Yolu

Türkiye
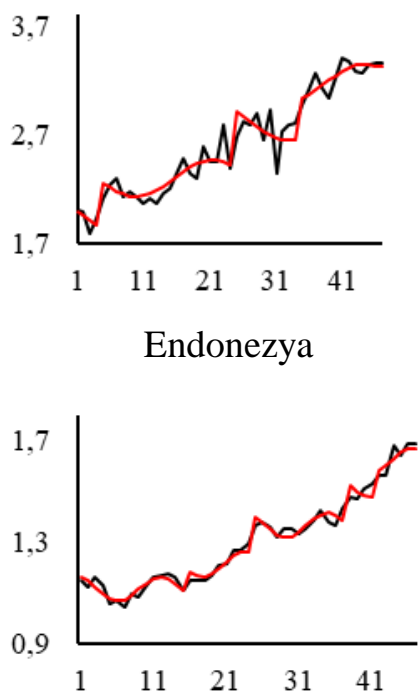

Meksika

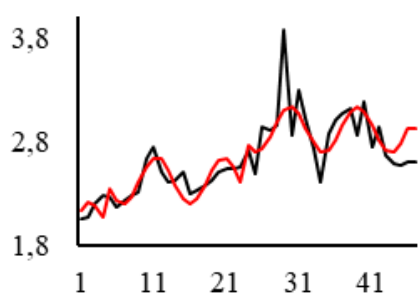

Filipinler
Bangladeş
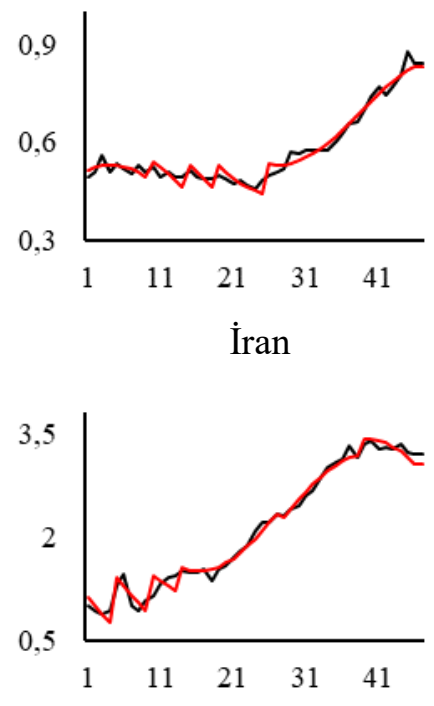

Nijerya

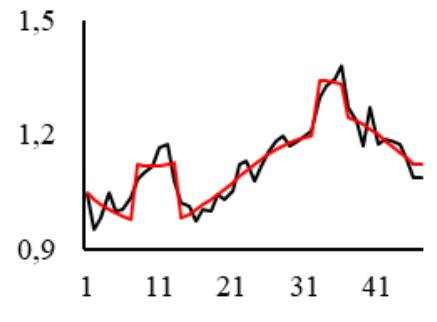

Vietnam

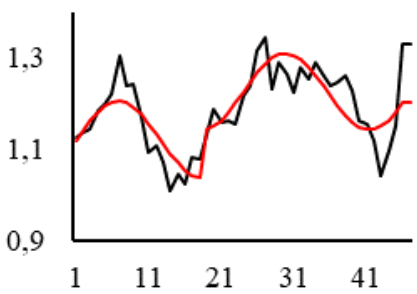

Misir
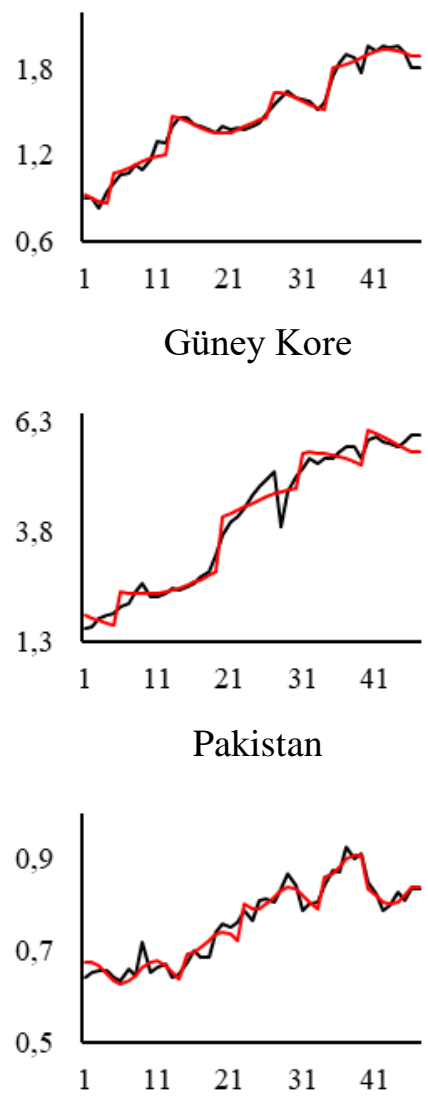

Şekil 1'de siyah renkli eğriler gerçek zaman yolunu, kırmızı renkli eğriler ise tahmini zaman yolunu temsil etmektedir. Sert ve yumuşak geçişlerle oluşturulan tahmini zaman yolu, gerçekleşen zaman yolunu güzel bir şekilde göstermektedir. $\mathrm{Bu}$ yüzden Fourier fonksiyonlarının analizde yer alması elde edilen sonuçların daha sağlıklı çıkmasına katkıda bulunacaktır. 
Tablo 5: Fourier-CBL Panel Birim Kök Testi Sonuçları

\begin{tabular}{|l|c|c|c|c|}
\hline Ülkeler & Barlett test istatistiği & $\mathbf{\% 1}$ & $\mathbf{\% 5}$ & $\mathbf{\% 1 0}$ \\
\hline Türkiye & 0,0778 & 0,0719 & 0,0546 & 0,047 \\
\hline Bangladeş & 0,2022 & 0,0843 & 0,0599 & 0,0493 \\
\hline Misır & 0,0708 & 0,0953 & 0,0698 & 0,0581 \\
\hline Endonezya & 0,0929 & 0,2106 & 0,1428 & 0,1111 \\
\hline İran & 0,0639 & 0,052 & 0,041 & 0,0363 \\
\hline Güney Kore & 0,0628 & 0,0624 & 0,0473 & 0,0411 \\
\hline Meksika & 0,1615 & 0,2193 & 0,1403 & 0,1103 \\
\hline Nijerya & 0,0942 & 0,0809 & 0,0616 & 0,0524 \\
\hline Pakistan & 0,062 & 0,1895 & 0,132 & 0,1034 \\
\hline Filipinler & 0,0271 & 0,1649 & 0,1108 & 0,0885 \\
\hline Vietnam & 0,215 & 0,1506 & 0,0959 & 0,0752 \\
\hline
\end{tabular}

Not: Tablo kritik değerleri elde edilirken 20.000 Monte Carlo simülasyonu kullanılmıştır.

F-istatistiği ile trigonometrik terimlerin anlamlılığına bakıldıktan ve sert geçişler tespit edildikten sonra EF'nin durağan olup olmadığı yumuşak geçişleri dikkate alan panel Fourier-CBL ve Vietnam'a ait Fourier fonksiyonları anlamsız çıktığı için trigonometrik terimleri dikkate almayan panel CADF yöntemleri ile test edilmiştir. Fourier-CBL ve CADF yöntemlerine ait sonuçlar sırasıyla Tablo 5 ve 6 'da yer almaktadır.

Tablo 6: CADF Birim Kök Testi Sonuçları

$\begin{array}{lcc}\text { Ülkeler } & \text { Test istatistiği } & \text { Optimal Gecikme } \\ \text { Türkiye } & -2,576 & 2 \\ \text { Bangladeş } & -0,181 & 2 \\ \text { Misir } & -2,380 & 1 \\ \text { Endonezya } & -1,571 & 1 \\ \text { İran } & \mathbf{- 3 , 7 7 4 * *} & \mathbf{1} \\ \text { Güney Kore } & \mathbf{- 3 , 6 0 7 * *} & \mathbf{1} \\ \text { Meksika } & -1,743 & 1 \\ \text { Nijerya } & -1,611 & 1 \\ \text { Pakistan } & -1,997 & 1 \\ \text { Filipinler } & -2,717 & 1 \\ \text { Vietnam } & 0,801 & 1\end{array}$

Not: CADF test istatistiği kritik değerleri \%1'de ve \%5'te sırasıyla $-4,11$ ve $-3,36$ 'dır (Pesaran, 2007: 275). **: \%5’te anlamll.

Tablo 5'teki sonuçlara göre Türkiye, Bangladeş, Misır, İran, Güney Kore, Meksika, Nijerya ve Vietnam'da serilerin birim kök içerdiği yani ıraksadığ 1 belirlenmiştir. Bu durum ilgili ülkelerde EF'de meydana gelen şokların ve ortaya çıkan çevresel kirliliğin etkisinin kalıcı olduğu anlamını taşımaktadır. Endonezya, Pakistan ve Filipinler'de serilerin durağan olduğu, yani yakınsadığ belirlenmiştir. $\mathrm{Bu}$ ülkelerde ise EF'de yaşanan şokların etkisi geçici olmaktadır. Tablo 6'daki sonuçlara göre yalnızca İran ve Güney Kore'de seriler durağan çıkmıştır. Bu testin 
sonucuna göre Vietnam'da Fourier-CBL durağanlık testinde olduğu gibi serilerin birim kök içerdiği belirlenmiştir. Fourier fonksiyonlarının kullanıldığ 1 birim kök testi geleneksel birim kök testlerine göre daha güvenilir olmaktadır. Bu yüzden serilerin yakınsayıp yakınsamadığının değerlendirilmesinde Fourier-CBL durağanlık testi daha gerçekçi sonuçlar verecektir.

\section{Sonuç}

Günümüzde çevresel kirliliğin yaşanmasında en önemli faktörlerin başında insan faaliyetleri gelmektedir. Geçmişte yaşanan çevresel sorunlar doğanın kendini yenileyebilme özelliğinden dolayı çok fazla gündeme gelmemiş ve bu sorunların kendi kendine ortadan kalkacağı öngörülmüştür. Günümüzde ise durum giderek kötü bir hal almaya başlamıştır. İnsan faaliyetlerinin doğa üzerinde oluşturduğu olumsuz baskı çevre kirliliklerinin artmasına ve geri döndürülemez bir hal almasına sebebiyet vermektedir. $\mathrm{Bu}$ yüzden çevre kirliliği konusunda son zamanlarda birçok çalışma yapılmaktadır. Bu çalışmalarda çevresel göstergeler belli başlı değişkenlerle ifade edilmektedir. $\mathrm{Bu}$ değişkenlerin başında da $\mathrm{CO}_{2}$ salımı gelmektedir. Fakat bu değişken tek başına çevresel kirliliği ifade etmede yetersiz kalabilmektedir. Çünkü $\mathrm{CO}_{2}$ salımı gibi birçok faktör çevresel tahribata neden olabilmektedir. Orman arazisi kullanımı, madencilik ve petrol stokları vb. faaliyetler de doğaya büyük bir tehdit unsuru oluşturmaktadır. Bu yüzden çevresel kirlilik faaliyetlerini araştırırken tek değişkenden ziyade birçok değişkeni içerisine alan kapsamlı bir göstergenin kullanılması elde edilecek sonuçların daha güvenilir olmasını sağlayacaktır. Bu bağlamda çevresel sürdürülebilirlik faaliyetlerini ölçmek için yaygın bir gösterge olarak kullanılan EF, kapsamlı bir değişkendir. Toprak ve su alanlarına yönelik insan talebinin ölçüsü olarak tanımlanan EF, BC ile karşılaştırılarak sürdürülebilir yaşam alanı hakkında bilgiye ulaşmamamızı sağlayabilmekte ve çevresel sonuçları anlamamıza katkıda bulunabilmektedir.

Bu çalışmada N11 ülkelerinde 1971-2016 döneminde kişi başına düşen EF'de meydana gelen şokların etkisinin geçici mi yoksa kalıcı mı olduğu araştırılmıştır. $\mathrm{Bu}$ bağlamda geleneksel birim kök testlerinden panel CADF ve yumuşak geçişlere izin veren panel Fourier-CBL durağanlık yöntemleri kullanılmıştır. Panel CADF yöntemine göre İran ve Güney Kore'de serilerin durağan olduğu belirlenmiştir. Geleneksel birim kök testlerine göre daha güvenilir sonuçlar veren, yapısal kırılmaları dikkate alan ve yumuşak geçişlere izin veren Fourier-CBL durağanlık yöntemine göre ise Endonezya, Pakistan ve Filipinler'de serilerin yakınsadığı, yani durağan olduğu sonucuna ulaşılmıştır. İlgili ülkelerde EF'de gerçekleşen şok etkisi geçici iken, birim kök içeren serilere sahip Türkiye, Bangladeş, Mısır, İran, Güney Kore, Meksika, Nijerya ve Vietnam'da ortaya çıkan şoklar telafisi mümkün olmayan kalıcı etkilere sebebiyet vermektedir.

N11 ülkelerinde ekolojik açık 1974 yılından itibaren başlamış ve giderek artmaya devam etmiştir. Bu yüzden özellikle bu sekiz ülkede çevre kirliliğini önlemek için uygun adımların atılması ve doğru politikaların uygulanması büyük önem arz etmektedir. Alınacak ortak kararlar çevresel politikaların uygulanmasında daha 
etkili ve verimli olacaktır. Karbon vergisi gibi çevre vergileriyle çevresel kirlilik baskı altına alınabilir. Bunun yanında sanayi üretiminin yoğun olarak gerçekleştirildiği N11 ülkelerinde fosil yakıt kullanımının yerine çevre kirliliğine sebebiyet vermeyen yenilenebilir enerji kaynakların tüketimi için gerekli altyapı çalışmaları hızlandırılmalıdır. Ekolojik açık azaldıkça toplumlar, geleceğe daha bir umutla bakacak ve gelecek nesillere temiz ve yaşanılacak bir çevre birakacaktır.

\section{Kaynakça}

Bahmani-Oskooee, M., Chang, T. ve Wu, T. (2014). Revisiting Purchasing Power Parity in African Countries: Panel Stationary Test with Sharp and Smooth Breaks. Applied Financial Economics, 24(22), 1429-1438.

Bahmani-Oskooee, M., Chang, T. ve Wu, T. P. (2015). Purchasing Power Parity in Transition Countries: Panel Stationary Test with Smooth and Sharp Breaks. International Journal of Financial Studies, 3(2), 153-161. doi: 10.3390/ijfs3020153.

Becker, R., Enders, W. ve Lee, J. (2006). A Stationarity Test in the Presence of an Unknown Number of Smooth Breaks. Journal of Time Series Analysis, 27(3), 381-409.

Bilgili, F., ve Ulucak, R. (2018). Is There Deterministic, Stochastic, and/or Club Convergence in Ecological Footprint Indicator among G20 Countries?" Environmental Science and Pollution Research, 25(35), 35404-35419.

Bilgili, F., Ulucak, R., ve Koçak, E. (2019). Implications of Environmental Convergence: Continental Evidence Based on Ecological Footprint. In Energy and Environmental Strategies in the Era of Globalization. Springer, Cham, 133-165.

Breusch, T. S. ve Pagan, A. R. (1980). The Lagrange Multiplier Test and Its Applications to Model Specification in Econometrics. The Review of Economic Studies, 47(1), 239-253.

Bu, M., Liu, Z., Wagner, M., ve Yu, X. (2013). Corporate Social Responsibility and the Pollution Haven Hypothesis: Evidence from Multinationals' Investment Decision in China. Asia-Pacific Journal of Accounting \& Economics, 20(1), 85-99.

Cai, Y., Chang, T., ve Inglesi-Lotz, R. (2018). Asymmetric Persistence in Convergence for Carbon Dioxide Emissions Based on Quantile Unit Root Test with Fourier Function. Energy, 161, 470-481.

Carrion-i-Silvestre, J. L., Del Barrio-Castro, T. ve López-Bazo, E. (2005). Breaking the Panels: An Application to the GDP Per Capita. The Econometrics Journal, 8(2), 159-175. 
Carrion-i-Silvestre, J. L., Kim, D., ve Perron, P. (2009). GLS-Based Unit Root Tests with Multiple Structural Breaks under both the Null and the Alternative Hypotheses. Econometric Theory, 25(6), 1754-1792.

Cucek, L., Klemes, J. J., ve Kravanja, Z. (2012). A Review of Footprint Analysis Tools for Monitoring Impacts on Sustainability. Journal of Cleaner Production, 34, 9-20.

DaMatta, F. M., Rahn, E., Läderach, P., Ghini, R., ve Ramalho, J. C. (2019). Why could the Coffee Crop Endure Climate Change and Global Warming to a Greater Extent than Previously Estimated?. Climatic Change, 152(1), 167-178.

Destek, M. A., ve Sarkodie, S. A. (2019). Investigation of Environmental Kuznets Curve for Ecological Footprint: the Role of Energy and Financial Development. Science of the Total Environment, 650, 2483-2489.

Dickey, D.A. ve Fuller, W.A. (1981). Likelihood Ratio Statistics for Autoregressive Time Series with a Unit Root. Econometrica: Journal of the Econometric Society, 49(4), 1057-1072.

Elliott, G., Rothenberg, T.J. ve Stock, J.H. (1996). Efficient Tests for an Autoregressive Unit Root. Econometrica, 64, 813-836.

Enders, W. ve Lee, J. (2012). The Flexible Fourier form and Dickey-Fuller Type Unit Root Tests. Economics Letters, 117(1), 196-199.

Gallant, A. R. (1981). On the Bias in Flexible Functional Forms and an Essentially Unbiased form: The Fourier Flexible Form. Journal of Econometrics, 15(2), 211-245.

Galli, A., Wiedmann, T., Ercin, E., Knoblauch, D., Ewing, B., ve Giljum, S. (2012). Integrating Ecological, Carbon and Water Footprint into a "Footprint Family" of Indicators: Definition and Role in Tracking Human Pressure on the Planet. Ecological Indicators, 16, 100-112.

Gil-Alana, L.A., Cunado, J., ve Gupta, R., 2017. Persistence, Mean-Reversion and Nonlinearities in $\mathrm{CO}_{2}$ Emissions: Evidence from the BRICS and G7 Countries. Environmental Resource Economics. 67(4), 869-883.

Gil-Alana, L. A., ve Solarin, S. A. (2018). Have US Environmental Policies been Effective in the Reduction of US Emissions? A new Approach Using Fractional Integration. Atmospheric Pollution Research, 9(1), 53-60.

Heil, M. T., ve Selden, T. M. (1999). Panel Stationarity with Structural Breaks: Carbon Emissions and GDP. Applied Economics Letters, 6(4), 223-225.

Jalil, A., ve Mahmud, S.F. (2009). Environment Kuznets Curve for $\mathrm{CO}_{2}$ Emissions: A Cointegration Analysis for China. Energy Policy, 37(12), 51675172. 
Javid, M., ve Sharif, F. (2016). Environmental Kuznets Curve and Financial Development in Pakistan. Renewable and Sustainable Energy Reviews, 54, 406-414.

Kwiatkowski, D., Phillips, P.C., Schmidt, P. ve Shin, Y. (1992). Testing the Null Hypothesis of Stationarity against the Alternative of a Unit Root: How Sure are We that Economic Time Series have a Unit Root?. Journal of Econometrics, 54, 159-178.

Lee, J. ve Strazicich, M.C. (2003). Minimum Lagrange Multiplier Unit Root Test with Two Structural Breaks. Review of Economics and Statistics, 85(4), 10821089.

Lee, C. C., ve Chang, C. P. (2009). Stochastic Convergence of Per Capita Carbon Dioxide Emissions and Multiple Structural Breaks in OECD countries. Economic Modelling, 26(6), 1375-1381.

List, J. A. (1999). Have Air Pollutant Emissions Converged among US regions? Evidence from Unit Root Tests. Southern Economic Journal, 144-155.

List, J., ve Strazicich, M. (2003). Are $\mathrm{CO}_{2}$ Emission Levels Converging among Industrial Countries?. Environmental and Resource Economics, 24, 263-271.

Lumsdaine, R.L. ve Papell, D.H. (1997). Multiple Trend Breaks and the UnitRoot Hypothesis. Review of Economics and Statistics, 79(2), 212-218.

Onater-Isberk, E. (2016). Environmental Kuznets Curve under Noncarbohydrate Energy. Renewable and Sustainable Energy Reviews, 64, 338-347.

Ozcan, B. ve Ozturk, I. (2016). A New Approach to Energy Consumption Per Capita Stationarity: Evidence from OECD Countries. Renewable and Sustainable Energy Reviews, 65, 332-344.

Ozcan, B., Ulucak, R., ve Dogan, E. (2019). Analyzing Long Lasting Effects of Environmental Policies: Evidence from Low, Middle and High Income Economies", Sustainable Cities and Society, 44, 130-143.

Panopoulou, E. ve T. Pantelidis (2007). Club Convergence in Carbon Dioxide Emissions. The Institute for International Integration Studies Discussion Paper Series iiisdp235, IIIS.E.

Pata, U. K. (2018). Renewable energy Consumption, Urbanization, Financial Development, Income and $\mathrm{CO}_{2}$ Emissions in Turkey: Testing EKC Hypothesis with Structural Breaks. Journal of Cleaner Production, 187, 770-779.

Pata, U. K. (2019). Environmental Kuznets Curve and Trade Openness in Turkey: Bootstrap ARDL Approach with a Structural Break. Environmental Science and Pollution Research, 26(20), 20264-20276.

Pata, U. K., ve Yurtkuran, S. (2018). Yenilenebilir Enerji Tüketimi, Nüfus Yoğunluğu ve Finansal Gelişmenin $\mathrm{CO}_{2}$ Salımına Etkisi: Türkiye Örneği. 
Uluslararası İktisadi ve İdari İncelemeler Dergisi, Prof. Dr. Harun Terzi Özel Say1s1, 303-318.

Perron, P. (1989). The Great Crash, the Oil Price Shock and the Unit Root Hypothesis. Econometrica, 57(6), 1361-1401.

Pesaran, M. H. 2004. General Diagnostic Tests for Cross Section Dependence in Panels. Cambridge Working Papers in Economics No. 435, University of Cambridge, and CESifo Working Paper Series No. 1229.

Pesaran, M.H. (2007). A Simple Panel Unit Root Test in the Presence of Cross-Section Dependence. Journal of Applied Econometrics, 22(2), 265-312.

Pesaran, M. H., Ullah, A. ve Yamagata, T. (2008). A Bias-Adjusted LM Test of Error Cross-Section Independence. The Econometrics Journal, 11(1), 105-127.

Phillips, P. C. ve Perron, P. (1988). Testing for a Unit Root in Time Series Regression. Biometrika, 75, 335-345.

Rees, William E. (1992). Ecological Footprints and Appropriated Carrying Capacity: What Urban Economics Leaves Out. Environmental Urbanization. 4(2), 121-130.

Salahuddin, M., Gow, J., ve Ozturk, I. (2015). Is the Long-Run relationship between Economic Growth, Electricity Consumption, Carbon Dioxide Emissions and Financial Development in Gulf Cooperation Council Countries robust?. Renewable and Sustainable Energy Reviews, 51, 317-326.

Shafiei, S., ve Salim, R. A. (2014). Non-Renewable and Renewable Energy Consumption and $\mathrm{CO}_{2}$ Emissions in OECD Countries: A Comparative Analysis. Energy Policy, 66, 547-556.

Shen, J., Wang, S., Liu, W., ve Chu, J. (2019). Does Migration of PollutionIntensive Industries Impact Environmental Efficiency? Evidence Supporting "Pollution Haven Hypothesis". Journal of Environmental Management, 242, 142-152.

Sidneva, N., ve Zivot, E. (2014). Evaluating the Impact of Environmental Policy on the Trend Behavior of US Emissions of Nitrogen Oxides and Volatile Organic Compounds. Natural Resource Modeling, 27(3), 311-337.

Solarin, S. A. (2019). Convergence in $\mathrm{CO}_{2}$ Emissions, Carbon Footprint and Ecological Footprint: Evidence from OECD Countries. Environmental Science and Pollution Research, 26(6), 6167-6181.

Solarin, S. A., Al-Mulali, U., Musah, I., ve Ozturk, I. (2017). Investigating the Pollution Haven Hypothesis in Ghana: An Empirical Investigation. Energy, 124, 706-719. 
Solarin, S. A., ve Bello, M. O. (2018). Persistence of Policy Shocks to an Environmental Degradation Index: The Case of Ecological Footprint in 128 Developed and Developing Countries. Ecological Indicators, 89, 35-44.

Solarin, S. A., Tiwari, A. K., ve Bello, M. O. (2019). A Multi-Country Convergence Analysis of Ecological Footprint and Its Components. Sustainable Cities and Society, 46, 101422.

Stegman, A. (2005). Convergence in Carbon Emissions Per Capita. Macquarie: Department of Economics, Macquarie University.

Tiwari, A. K., Kyophilavong, P., ve Albulescu, C. T. (2016). Testing the Stationarity of $\mathrm{CO}_{2}$ Emissions Series in Sub-Saharan African Countries by Incorporating Nonlinearity and Smooth Breaks. Research in International Business and Finance, 37, 527-540.

Ulucak, R., ve Apergis, N. (2018), Does Convergence Really Matter for the Environment? An Application based on Club Convergence and on the Ecological Footprint Concept for the EU Countries, Environmental Science \& Policy, 80, 21-27.

Ulucak, R., ve Bilgili, F. (2018). A Reinvestigation of EKC Model by Ecological Footprint Measurement for High, Middle and Low Income Countries. Journal of Cleaner Production, 188, 144-157.

Wachernagel, Mathis, Rees, William, 1996. Our Ecological Footprint: Reducing Human Impact on the Earth. The New Catalyst Bioregional Series. New Society Publishers.

Wang, S., Li, Q., Fang, C., ve Zhou, C. (2016). The Relationship between Economic Growth, Energy Consumption, and $\mathrm{CO}_{2}$ Emissions: Empirical Evidence from China. Science of the Total Environment, 542, 360-371.

Yilanci, V., Gorus, M. S., ve Aydin, M. (2019). Are Shocks to Ecological Footprint in OECD Countries Permanent or Temporary?. Journal of Cleaner Production, 212, 270-301.

Yurtkuran, S., ve Terzi, H. (2018). Çevresel Kuznets Eğrisinin Ampirik Olarak Analizi: Meksika Örneği. Uluslararası İktisadi ve İdari İncelemeler Dergisi, 20, 267-284.

Zheng, D., ve Shi, M. (2017). Multiple Environmental Policies and Pollution Haven Hypothesis: Evidence from China's Polluting Industries. Journal of Cleaner Production, 141, 295-304.

Zivot, E. ve Andrews, D.W.K. (1992). Further Evidence on the Great Crash, the Oil-Price Shock, and the Unit-Root Hypothesis. Journal of Business and Economic Statistics, 10(3), 251-270. 